\title{
A EDUCAÇÃO PROFISSIONAL NAS LEIS DE DIRETRIZES E BASES DA EDUCAÇÃO: PONTOS E CONTRAPONTOS
}

\author{
O. M. MEDEIROS NETA ${ }^{1,2,{ }^{*}}$, M. L. PEREIRA ${ }^{2}$, S. R. ROCHA ${ }^{3}$, F. L. S. NASCIMENTO ${ }^{4}$ \\ ${ }^{1}$ Universidade Federal do Rio Grande do Norte, ${ }^{2,3,4}$ Instituto Federal do Rio Grande do Norte - Campus Natal- \\ Central \\ olivianeta@yahoo.com.br*
}

Submetido 22/02/2018 - Aceito 28/05/2018

DOI: $10.15628 /$ holos.2018.6982

\section{RESUMO}

O objetivo deste trabalho é discutir a educação profissional nas Leis de Diretrizes e Bases da Educação Nacional (LDB), destacando a visibilidade, direcionamento e assunção desse campo educacional na legislação que estabelece as bases educacionais do Brasil. A metodologia consistiu na categorização das LDB, em articulação com decretos e pareceres, problematizados à luz dos pressupostos teóricos dos autores: Ciavatta (2005); Machado (2013), Manfredi (2002), Moura (2007), Frigotto (2010), entre outros. As categorias analisadas são trabalho e educação, estrutura e organização da educação profissional, formação humana e formação docente. Os resultados dessa análise possibilitaram a seguinte conclusão: a educação profissional não foi priorizada em benefício do desenvolvimento social, mas sim do capital, uma vez que os interesses das empresas privadas e do desenvolvimento econômico se sobressaíram nas políticas públicas educacionais; as Leis n. 4.024/61, 5.692/71 e 9.394/96 mantiveram a dualidade estrutural, portanto, a formação humana integral, apesar de ser referida nas LDB, não se materializou na prática; no tocante à formação docente, predominou uma reticência nas $L D B$, com o objetivo de não comprometer o Estado com o necessário investimento financeiro que esse tema exige, dada as especificidades do campo da educação profissional.

PALAVRAS-CHAVE: educação profissional, formação docente, formação humana integral, Leis de Diretrizes e Bases da Educação Nacional.

\section{THE PROFESSIONAL EDUCATION IN THE BRAZILIAN EDUCATIONAL LAW: POINTS E COUNTERPOINTS}

\section{ABSTRACT}

This work aims to discuss the professional educational trough the analysis of Brazilian educational laws point out the visibility, direction and assumption of this educational field. The methodology parts from the theories developed by Ciavatta (2005); Machado (2013), Manfredi (2002), Moura (2007), Frigotto (2010) and other, to analyze the Brazilian Educational Law (LDB), in articulation with decrees and technical advices. The analyzed categories are work and education, structure and organization of professional education, human formation and teacher's training. The results of this analysis lead to the following conclusion: professional educational was not prioritized as part of social development, but under capital interests, the private corporations and the economic development are the focus of the public educational politics, such as the laws 4.024/61, 5.692/71 and 9.394/96. These laws kept the structural duality of the professional education, although they mention integral human formation, this was not put into practice. Teacher's training is also kept aside of these laws, that tend to avoid the necessary financial investment that State had to perform in order to attend the professional education field.

KEYWORDS: professional education, teacher's training, integral human education, Brazilian Educational Law (LDB). 


\section{INTRODUÇÃO}

O objetivo deste texto é discutir a educação profissional nas Leis de Diretrizes e Bases da Educação Nacional (LDB), destacando a visibilidade, direcionamento e assunção desse campo educacional na legislação que estabelece as bases educacionais do Brasil.

Essas LDB estão situadas em contextos históricos expressivos, ora de disputas entre a sociedade e o capital, ora de hegemonia do último. A primeira LDB, Lei n. 4.024/61, resultou do primeiro período de redemocratização do país, que sucedeu ao Estado Novo. Já a segunda, Lei n. $5.692 / 71^{1}$, é fruto do regime ditatorial, quando em 1964 , militares destituíram o governo de João Goulart, assumindo o comando do país. A terceira LDB, Lei n. 9.394/96, decorre das disputas políticas proporcionadas pelo processo de redemocratização do país nos anos 1980, quando ocorreu a instituição de uma nova constituinte, a partir da qual esperava-se novos rumos para a sociedade e consequentemente para a educação.

A construção deste texto iniciou-se pela leitura e categorização das LDB, em articulação com decretos e pareceres, problematizados à luz dos pressupostos teóricos dos seguintes autores(as): Ciavatta (2005), Machado (2013), Manfredi (2002), Moura (2007), Frigotto (2010), entre outros.

Destacamos as categorias trabalho e educação, estrutura e organização da educação profissional, formação humana e formação docente, as quais decorrem inicialmente das inquietações que impulsionaram este estudo, considerando os pressupostos teóricos que orientam nossa discussão e a necessidade de investigar o lugar da educação profissional na legislação que estabelece as diretrizes educacionais no Brasil, desde a década de 60 .

Dispomos da Análise Textual Discursiva (ATD) sob a perspectiva de Moraes e Galiazzi (2016), os quais a definem como uma metodologia analítica para fins de investigação de natureza qualitativa com o propósito de produzir novos conhecimentos sobre os fenômenos e discursos.

Por meio da ATD foi possível analisar as partes para compreender o todo pelo processo de categorização, dessa forma, a análise do discurso permitiu desvendar sentidos e novas compreensões, considerando o contexto no qual foi produzido e as intencionalidades dos autores desse discurso. O movimento discursivo de descrição e interpretação nos conduziu à compreensão do material analisado (as Leis) e os fenômenos produzidos a partir de suas diretrizes.

Estruturamos a discussão em três tópicos: LDB n. 4.024/61: a ratificação das Leis Orgânicas; A profissionalização da Educação na LDB n. 5.692/71; e LDB 9.324/96: disputas entre a sociedade e o capital.

\footnotetext{
${ }^{1}$ A Lei no 5.692/71 trata apenas da Educação nos níveis básicos, não fazendo nenhuma menção a Educação Superior, mesmo essa tendo sido alterada pela Lei no 5540/68 por meio da Reforma Universitária. Por essa razão, alguns autores não a consideram como LDB, apenas uma reforma da organização dos 10 e $2 \circ$ graus.
} 


\section{LDB N. 4.024/61: A RATIFICAÇÃO DAS LEIS ORGÂNICAS}

Para debatermos sobre a lei n. 4.024/61 é necessário revisar a estrutura da educação profissional estabelecida no início dos anos 1940, nas Leis Orgânicas de Ensino, as quais emergiram da Reforma Capanema, no governo ditatorial de Getúlio Vargas. Essas leis reproduziam a dualidade histórica da educação profissional ${ }^{2}$, sempre vinculada à formação da classe trabalhadora para trabalhos manuais, enquanto à classe dirigente, destinava-se o ensino propedêutico, cuja finalidade é o trabalho intelectual.

Esse conjunto de leis, além de fortalecer a dualidade estrutural, delineavam uma dualidade interna de acordo com a seguinte organização: o ensino primário era estruturado a partir de um currículo único, embora houvesse diferença na qualidade da oferta, cujo acesso reproduzia a divisão de classe na sociedade. No entanto, essa dualidade se manifestava de forma contundente no 10 ciclo do Ensino Médio, que equivale na organização atual, aos anos finais do Ensino Fundamental. Nesse estágio, o currículo era profissionalizante, com exceção do Curso Ginasial Secundário, que dava acesso ao 2 o ciclo do ramo propedêutico, o qual equivale atualmente à última etapa da educação básica. Já os outros ramos - Curso Normal, Curso Básico Industrial, Curso Básico Comercial e Curso Básico Agrícola não permitiam a continuidade dos estudos propedêuticos e consequentemente impediam a escolha de outra profissão no 20 ciclo ou no Ensino Superior, pois tudo já se definia no 1 o ciclo, quando os estudantes ainda eram crianças, conforme explicita Manfredi (2002).

Nesse cenário de exclusão, as reivindicações populares exercem um importante papel no tocante à superação da dualidade interna e ao adiamento da escolha profissional. A conquista da equivalência entre os primeiros ciclos dos diferentes ramos do então Ensino Médio se materializou na possibilidade de os alunos do primeiro ciclo de qualquer ramo terem acesso ao segundo ciclo secundário, normatizado pela Lei n. 1.076/50, e pela igualdade de acesso ao vestibular, conquistada pela Lei n. 1.821/53.

Isso foi possível mediante disputas empreitadas por movimentos sociais, culturais e políticos, os quais na fase de redemocratização encontram ambientação profícua para a luta de interesses da classe trabalhadora. A primeira LDB é gerada nesse contexto, resultante de embates de grandes personalidades em defesa daqueles interesses, entre as quais se incluem Anísio Teixeira e Paulo Freire (Assis \& Medeiros Neta, 2015).

A LDB n. 4.024/61 oficializa a equivalência já normatizada pela Lei n. 1.076/50. Assim, define no Art. 12: Os sistemas de ensino atenderão à variedade dos cursos, à flexibilidade dos currículos e à articulação dos diversos graus e ramos; no artigo 35, também se evidencia a equivalência: $\S 300$ currículo das duas primeiras séries do $1^{\circ}$ ciclo será comum a todos os cursos de ensino médio no que se refere às matérias obrigatórias; e ainda no Art. 37: Para matrícula na 1a série do ciclo colegial, será exigida conclusão do ciclo ginasial ou equivalente.

\footnotetext{
${ }^{2}$ Indicação de leitura: MOURA, Dante Henrique. Educação básica e educação profissional e tecnológica: dualidade histórica e perspectiva de integração. Holos, Natal, v. 2, p. 1-27, 2007. Disponível em: http://www2.ifrn.edu.br/ojs/index.php/HOLOS/article/viewFile/11/110 .
} 
Apesar do avanço, a dualidade se mantém, uma vez que permanece a estrutura ensino secundário e ensino técnico no 2o ciclo do Ensino Médio, o primeiro reservado ao ensino propedêutico e o segundo, ao ensino profissionalizante, nos cursos já mencionados. De uma forma geral, o ramo propedêutico era o eleito pelos estudantes que não precisam trabalhar antes do curso superior, enquanto os filhos da classe trabalhadora abraçavam a profissionalização precocemente, devido às necessidades socioeconômicas.

\subsection{Estrutura e organização da educação profissional: mudança ou conservação?}

O título VII da primeira LDB delineia a organização da EP, cuja estrutura é semelhante às definidas pelas leis orgânicas dos anos 1940, com as alterações preceituadas pelas normas e legislação publicadas nos anos 1950, a exemplo das duas leis mencionadas anteriormente (Lei $n$. 4.024, 1961).

Destarte, o Ensino Médio ou Grau Médio se organizava em dois ciclos com disciplinas e práticas educativas de caráter obrigatório e optativo (para os estabelecimentos de ensino). 01 은 ciclo, o ginásio com duração de 4 anos e o 20 ciclo, o colegial, que se subdivide em ensino secundário, ensino técnico e os cursos de formação de professores para lecionarem no ensino pré-primário e primário, conforme o normatizado naquele título. Das opções apresentadas, apenas o ensino secundário não apresenta caráter profissionalizante, uma vez que sua finalidade era propedêutica.

Dessa forma, a Educação Profissional está prescrita nos capítulos III e IV do título VII, que tratam do ensino técnico e da formação do magistério para o ensino primário e médio, respectivamente. 0 artigo 47 preceitua três cursos técnicos: industrial; agrícola; comercial. Essa LDB ratifica o modelo de educação do Estado Novo, que se compromete com o desenvolvimento econômico, formando força de trabalho para atuar nos três setores da economia, o primário, o secundário e o terciário. O que nos leva a interpretação de que essa divisão do trabalho imposta na oferta educacional é uma forma de impelir os cidadãos a contribuir "com a obra do bem comum", texto que compõe a alínea "d" do artigo 10 da LDB em questão.

O artigo 51 desse capítulo trata também da obrigação das empresas de ofertarem aos menores aprendizes cursos de aprendizagem e técnicas de ofícios em cooperação com os sistemas de ensino. Os certificados ou as cartas de ofícios relativas a esses cursos habilitavam a matrícula no ginásio do ensino técnico correspondente, mediante exame de habilitação. Percebemos nesse artigo da Lei a articulação do Estado com as empresas no propósito de desenvolver força de trabalho apta às novas configurações do desenvolvimento industrial.

O capítulo IV integra a organização da Educação Profissional de nível médio e trata da formação do magistério para o Ensino Primário e Médio. Estabelece que o Ensino Normal tem como finalidade a formação de professores, orientadores, supervisores e administradores escolares destinados ao ensino primário, e o desenvolvimento dos conhecimentos técnicos relativos à educação da infância. O grau ginasial habilitava para a regência no Ensino Primário, enquanto o colegial, para a docência naquele mesmo nível (Lei n. 4.024, 1961). 
A LDB possibilitou o acesso do ginásio para o colegial entre qualquer um dos ramos, mas apesar disso, a dualidade se mantém, uma vez que continuou a mesma organização do sistema educacional. Ou seja, tornava-se mais fácil o acesso a qualquer curso superior para aqueles que seguiam o ramo propedêutico. Em relação aos demais, poucos concluíam o 2o ciclo do grau médio.

\subsection{Formação humana para o mercado de trabalho}

O primeiro artigo da Lei n. 4.024/61, em sua alínea " $d$ " dispõe da seguinte redação: Art. 1: A educação nacional, inspirada nos princípios de liberdade e nos ideais de solidariedade humana, tem por fim: d) o desenvolvimento integral da personalidade humana e sua participação na obra do bem comum.

Uma leitura isolada da primeira parte desta alínea nos informa a possibilidade de uma educação comprometida com a formação humana em todas as suas dimensões, já a segunda parte, que se refere a participação na obra do bem comum, não explicita os termos desse bem comum, embora o conjunto da lei evidencie uma relação entre educação e trabalho, materializada na produção de força de trabalho para as necessidades do modo de produção capitalista.

Em outros termos, a preocupação governamental era preparar medianamente os jovens brasileiros para atender às demandas dos três setores da economia, no período em que o desenvolvimento industrial do país, impulsionado pelo crescimento econômico ocorrido após a Segunda Guerra Mundial, exigia conhecimentos técnicos, de acordo com o fordismo-taylorismo.

$\mathrm{Na}$ realidade, a formação humana integral não existia em nenhum dos ramos. Isso é perceptível na forma como a organização da educação profissional é estruturada, enquanto o ensino técnico preparava para o trabalho operacional, o ensino secundário possibilitava à ascensão ao ensino superior. Não havia a preocupação em atender todas as dimensões da formação humana de forma integrada.

2.3 A FORMAÇÃO de professores para atuar na educação profissional: os cursos especiais e suas repercussões

O Art. 59 da Lei n. 4.024/61 normatizava a formação de professores para atuar no Ensino Médio, distinguindo o lócus de formação de acordo com a área em que atuavam. Os professores do ensino propedêutico deveriam se formar nas faculdades de Ciências, Letras e Artes, já aqueles que lecionavam disciplinas específicas no ensino técnico deveriam formar-se em cursos especiais de educação técnica.

Essa breve previsão de cursos especiais constante na LDB n. 4.024/61 gerou diversas interpretações, materializadas em pareceres e portarias. Machado (2013) aponta os cursos 
especiais preceituados nessa LDB como a referência mais importante que se tem até a atualidade sobre formação doente para a educação profissional.

Essa autora expõe diversos pareceres e portarias pautados naquela prescrição legal. 0 primeiro deles, o Parecer n. 257/63, que aprovou o Curso Especial em Cultura Feminina, o qual se destinava à formação de professoras para o Curso de Economia Doméstica e Trabalhos Manuais; na sequência, a Portaria Interministerial n. 174/65, que determinava a carga horária mínima de 800 aulas, distribuídas no mínimo em 180 dias para os cursos de Didática Geral do Ensino Agrícola; outro fato importante decorrente da redação do artigo 59 foi a criação da Universidade do Trabalho Industrial de Minas Gerais (Utramig), cuja finalidade era a preparação de professores para o ensino industrial.

Já em 1967, uma nova interpretação é dada aos cursos especiais normatizados naquela LDB. O Parecer CFE N. 12/67 explica que os Cursos Especiais de Educação Técnica eram cursos destinados a formação de professores de disciplinas específicas. Isso gerou uma problemática, dada a especificidade das múltiplas demandas do ensino técnico, cuja diversidade curricular dificulta a implementação dos programas de formação docente. Por essa razão, em 1968, o MEC publica a Portaria Ministerial n. 111/68, para esclarecer que os cursos especiais se destinam à formação de professores para as disciplinas específicas, portadores de diploma de nível superior ou nível médio técnico. No mesmo ano, o Parecer CFE n. 49/68 estabelece um currículo mínimo para esses cursos (Machado, 2013).

À vista disso, a Lei n. 4.024/61 tem o papel de ratificar as modificações ocorridas durante os períodos que correspondem ao Estado Novo e à redemocratização do país, no tocante a construção de políticas para a educação profissional no Brasil. No final dos anos 1960, em plena ditadura, o país passa por modificações e a educação é vista como protagonista do projeto de desenvolvimento industrial. Na próxima seção, discutimos a LDB n. 5.692/71 e as alterações controversas que ocorreram na educação profissional.

\section{A PROFISSIONALIZAÇÃO DA EDUCAÇÃO NA LDB N. 5.692/71}

É importante contextualizarmos o período político e econômico que vivia o país no período de 1964 a 1985. Em 1964, militares (contrários ao Governo João Goulart) o destituíram do cargo por meio de um golpe, assumindo o comando do país, instituindo um regime ditatorial. No contexto da Economia, o Presidente Emílio Garrastazu Médice ${ }^{3}$ impôs um projeto desenvolvimentista, que prometia inserir o país na elite da economia mundial.

O denominado milagre econômico se caracterizou por um conjunto de políticas sociais e econômicas as quais contribuíram para melhores condições estruturais do país e para o crescimento do Produto Interno Bruto (PIB), mas, contraditoriamente, só promovia riqueza aos grandes proprietários agrários e às burguesias urbanas, enquanto os trabalhadores continuavam imersos na pobreza, sob altas taxas de juros e de carga inflacionária, aumentando ainda mais o abismo entre pobres e ricos.

\footnotetext{
${ }^{3}$ O Presidente Emílio Garrastazu Médice governou o Brasil no período de 1969 a 1974.
} 
O Brasil disputava a participação na economia internacional, sendo assim, a profissionalização da educação iria promover a formação de recursos humanos para serem absorvidos pelo mercado de trabalho. Por meio de reformas e leis, a educação no Brasil estava em absoluto alinhamento com a teoria do capital humano, na qual a formação humana é considerada um investimento pessoal, que traz como retorno o crescimento econômico e, em consequência disso, promove o aumento da renda pessoal e a ascensão social.

Nessa situação, o papel da escola se restringia à função de produzir um conjunto de habilidades tecnicistas a serviço do desenvolvimento econômico, bem como do desenvolvimento do indivíduo, que ao se valorizar estaria valorizando o capital. A teoria do capital humano pôs sobre o indivíduo a responsabilidade de inserção social, de empregabilidade e de desempenho profissional, fazendo da educação um valor econômico. Como afirma Frigotto (1993. p. 41): "a educação passa, então, a constituir-se num dos fatores fundamentais para explicar economicamente as diferenças de capacidade de trabalho e, consequentemente, as diferenças de produtividade e renda."

Sob esse momento histórico é promulgada a segunda LDB, Lei n. 5.692 de 11 de agosto de 1971, que instituiu a profissionalização universal e compulsória para o ensino secundário, equiparando cursos secundários e cursos técnicos (Manfredi, 2002). Sob essa perspectiva, nessa seção, discutimos as controvérsias dessa lei e seus propósitos.

Gamboa (2001), ao se referir aos papéis da Educação na sociedade globalizada compreende que, no contexto da revolução informacional, ou mais precisamente da globalização, observam-se novas divisões do trabalho, a denominada divisão internacional do trabalho, nela a educação mantém-se, como sempre, atrelada aos interesses dominantes do capital. Aos países da América Latina, países de terceiro mundo, resta a formação tecnificada para fornecer força de trabalho barata. Aos países de primeiro mundo e cidadãos donos do capital, uma formação nas mais privilegiadas universidades do mundo, de modo a desempenhar as altas tarefas da economia e do Estado, restando perspectivas sombrias para a educação pública, especialmente a oferecida pelos países periféricos como o Brasil.

Analisamos essa lei a partir das categorias que situamos na introdução deste trabalho, discutindo os aspectos contraditórios em relação ao que essa lei ambicionava: pôr fim à dualidade educacional no país, conforme destaca Assis e Medeiros Neta (2015).

\subsection{ORGANIZAÇÃO e estrutura da educação profissional}

As mudanças se concentraram na educação de grau primário e de grau médio, mais especificamente nos cursos que até então eram denominados primário, ginasial e colegial, modificaram-se para 1ㅇ e 2ㅇ grau. 010 grau agregou o primário e o ginásio, passando a ter oito anos, e o $2^{\circ}$ grau três anos, correspondentes as três séries da última etapa da educação básica.

No contexto da organização e estrutura da educação profissional preconizada na Lei n. 5.692/71 em seu Art. 5, parágrafos 1ํㅜ e 2ํㅜ, preveem em seus currículos: 
$\S 1$ ㅇ Observadas as normas de cada sistema de ensino, o currículo pleno terá uma parte de educação geral e outra de formação especial, sendo organizado de modo que:

a) no ensino de primeiro grau, a parte de educação geral seja exclusiva nas séries iniciais e predominantes nas finais;

b) no ensino de segundo grau, predomine a parte de formação especial. $\S 2$ 2 A parte de formação especial de currículo:

a) terá o objetivo de sondagem de aptidões e iniciarão para o trabalho, no ensino de 10 grau e de habilitação profissional, no ensino de $2 \circ$ grau;

b) será fixada, quando se destine a iniciação e habilitação profissional, em consonância com as necessidades do mercado de trabalho local ou regional, à vista de levantamentos periodicamente renovados. (Lei n. 5.692, 1971, grifo nosso).

Ou seja, um currículo que, no ensino de primeiro grau sejam feitas sondagens de aptidões profissionais e no segundo grau, a habilitação profissional técnica; além disso, que atenda as demandas imediatas do mercado local, destituído dos preceitos de formação humana integral.

Moura (2007) destaca três aspectos nessa reforma, que tangenciaram a estrutura da educação no país:

- O primeiro deles foi a integração do ginasial a fase inicial da escolarização;

- O segundo foi a extinção do exame de admissão, fruto da integração do ginásio à primeira fase da escolarização. O que pode ser considerado positivo, pois o exame promovia a exclusão e o impedimento do prosseguimento dos estudos de uma imensa maioria dos filhos das camadas populares;

- O terceiro foi a polêmica e, ao mesmo tempo, relevante, profissionalização do ensino de 2o grau.

Polêmica porque na prática a profissionalização do segundo grau na verdade serviria para atender às expectativas do milagre econômico, que, de acordo com Moura (2007, p.12), "demandava por mão de obra qualificada (técnicos de nível médio) para atender a tal crescimento". Outro ponto polêmico foi o Parecer n. 76/75 do CFE, e em seguida, a Lei n.

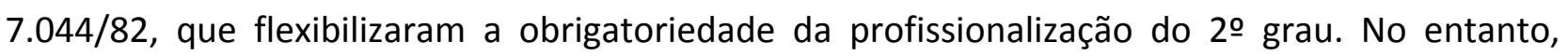
apenas a rede pública continuou seguindo essa legislação (bastante deficiente na rede estadual), pois na rede privada prevalecia o ensino propedêutico, dando condições àqueles que nele se inseriam de prosseguimento nos estudos em nível superior.

\subsection{O PROPÓSITO explícito de formar para o mercado de trabalho}

No Art. 1 da Lei n. 5.692/71, o texto já deixa claro o papel assumido pela educação nesse contexto de formar força de trabalho que atenda às demandas do mercado, o qual vivia seu período de expansão na economia brasileira. Esse artigo da Lei revela essa intencionalidade: 0 ensino de 10 e 20 graus tem por objetivo geral proporcionar ao educando a formação necessária 
ao desenvolvimento de suas potencialidades como elemento de autorrealização, qualificação para o trabalho e preparo para o exercício consciente da cidadania. (Lei n. 5.692, 1971, grifo nosso).

No contexto dessa reforma, seguimos o entendimento de Gamboa (2001). Esse autor, ao discutir sobre as disputas político-econômicas na sociedade capitalista, destaca que a educação é posta para servir ao modelo hegemônico e não às classes trabalhadoras, promovendo uma expansão do tecnicismo educativo ligado aos interesses capitalistas de formação do homo faber em grande escala, com mão de obra tecnificada, barata e em abundância.

O que fica bastante evidenciado no Art. 4 dessa Lei: os currículos do ensino de 1 ㅇ e 2 은 graus terão um núcleo comum, obrigatório em âmbito nacional, e uma parte diversificada para atender, conforme as necessidades e possibilidades concretas, às peculiaridades locais, aos planos dos estabelecimentos e às diferenças individuais dos alunos. Ou seja, os sujeitos eram preparados para atender a essas demandas locais. Não obstante ser uma formação tecnicista, unilateral, ela era também geograficamente limitada.

O Art. 21 prescreve o termo "formação integral do adolescente", destituído da palavra humana, e em alinhamento ao Art. 1, como já discutido, deixa evidente que a universalização e obrigação da profissionalização do ensino secundário não contempla a formação humana integrada, na perspectiva preconizada por Gramsci: uma formação que integre o sujeito físico, mental, cultural, político e científico-tecnológico (Ciavatta, 2005). Ao contrário, atende ao preparo de jovens para inserção no mercado de trabalho, sob as determinações das demandas locais.

Nesse sentido, alinhamo-nos ao entendimento de Frigotto (2010, p.30) quando destaca que "a profissionalização compulsória do Ensino Médio e a formação técnico-profissional foram consideradas dentro de uma perspectiva para adestrar e ensinar o que serve ao mercado." Dessa forma, distancia-se diametralmente da formação omnilateral, possível em um currículo que contemple a ciência, a cultura, a tecnologia e o trabalho.

Costa e Nascimento (2013) afirmam que uma formação humana integrada deve apontar para uma formação do sujeito para a vida, convergindo os espaços do mundo do trabalho e do fazer científico no mesmo programa educacional. Isso não aconteceu no ensino técnico profissionalizante da Lei n. 5.692/71, na contramão, objetivava formar mão de obra aligeirada e baixo custo para promover o desenvolvimento da economia do país, essa assentada nas mãos das elites.

\subsection{A DESVALORIZAÇÃO da formação docente}

A respeito da exigência mínima para atuação na educação de nível básica, a Lei $n$. 5.692/71 estabelecia que:

a) no ensino de 1으 grau, da 1a à $4 \underline{a}$ séries, habilitação específica de 2ํo grau; 
b) no ensino de 10 grau, da 1a à 8 a séries, habilitação específica de grau superior, ao nível de graduação, representada por licenciatura de 10 grau, obtida em curso de curta duração;

c) em todo o ensino de 10 e 20 graus, habilitação específica obtida em curso superior de graduação correspondente a licenciatura plena. (Lei n. 5.692, 1971)

Com a profissionalização no ensino do 2ำ grau obrigatória, Machado (2013) informa que isso gerou um aumento na demanda por professores para as disciplinas técnicas, no entanto não ficava claro na Lei qual a formação mínima que estes deveriam ter.

Com a portaria Ministerial n. 432/71 foram criados cursos emergenciais para atender a essa demanda, buscando formar de forma aligeirada, professores para as disciplinas específicas do 20 Grau, originam-se assim os Esquemas I e II. "O Esquema I destinado à complementação pedagógica de portadores de diplomas de nível superior, enquanto o Esquema II, aos portadores de diploma técnico industrial de nível médio. Para estes últimos, além das disciplinas do Esquema I, eram necessárias disciplinas de conteúdos correlativas (Rodrigues \& Souza, 2015 p. 629), caracterizando uma formação aligeirada e desconectada do que regia a Lei n. 5.692/71, flexibilizando a formação docente.

Além das controvérsias do próprio texto da Lei, que ambicionava superar a dualidade histórica da educação brasileira a partir da obrigatoriedade da profissionalização na educação de segundo grau, o projeto esbarrou na falta de estrutura e de recursos humanos que possibilitassem essa inserção na rede estadual e municipal de ensino (onde ocorriam o maior número de matrículas). Assis e Medeiros Nata $(2015$, p.201) resumem o aprofundamento dessa dualidade:

\begin{abstract}
A dualidade que se pretendia eliminar configurava-se muito mais nítida, aprofundando a cisão entre ensino público e privado, uma vez que as escolas privadas seguiram com seus currículos propedêuticos e as públicas estaduais passaram a oferecer um ensino profissional de baixa qualidade. Isso se deveu também a flexibilização da Lei $n^{\circ}$ 5.692/71 pelo Parecer $n^{\circ}$ 76/1975, do Conselho Federal de Educação, seguido da Lei $n^{\circ} 7.044 / 1982$ que facultaram a obrigatoriedade da profissionalização em todo o ensino de $2^{\circ}$ grau.
\end{abstract}

Em decorrência dessa situação, o Decreto n. 7.044/82 flexibilizou a oferta compulsória, pois na prática a obrigatoriedade ocorria apenas na rede pública. A pressão das instituições privadas de ensino, a falta de estrutura e de profissionais preparados para atuar nesse modelo de educação forçou gradativamente uma postura política do governo, cuja iniciativa foi o Parecer $n$. $76 / 75$ do CFE que flexibilizava a oferta de educação profissional e propedêutica e em 82 , o decreto já mencionado.

Desse modo, a obrigatoriedade compulsória de profissionalização do segundo grau vai desaparecendo, ficando restrita às escolas federais, ao sistema $\mathrm{S}$ e a instituições privadas. 
Com o advento da terceira LDB, Lei n. 9.394/1996, as discussões sobre a educação profissional são retomadas, impulsionadas pela redemocratização do país e pela Constituição Federal de 1988.

\section{LDB 9.394/96: DISPUTAS ENTRE A SOCIEDADE E O CAPITAL}

Nos anos 1980 do século XX, o Brasil vivenciava o segundo ciclo de redemocratização que marcou a superação da ditadura ocorrida no século no período de 1964 a 1985. Da mesma forma que no primeiro ciclo (entre as décadas de 40 e 60), as condições de disputa entre as categorias capital e trabalho eclodiram. A proposta da terceira LDB decorre, do ponto de vista formal e legal, do Art. 22, inciso XXIV da Constituição Federal/88, que determina a competência da União para legislar sobre as diretrizes e bases da educação nacional.

Entre as questões que traziam a insatisfação da sociedade, faziam-se contundentes a conservação da dualidade estrutural na educação; o expressivo índice de reprovação; o monopólio do setor empresarial no campo do ensino e da capacitação (o Sistema S, Senai/Senac, se beneficiou da capacitação técnica, além das empresas serem subsidiadas pelo poder público para ofertar cursos); políticas de capacitação direcionadas para o interesse do capital, em detrimento do desenvolvimento social e da distribuição de renda (Manfredi, 2002).

Todos esses elementos foram determinantes na proposição da Lei n. 9.394/96, empreendida por dois projetos, um da câmara, proposto pelo deputado Otávio Elísio em 1988, e outro do senado, proposto pelo senador Darcy Ribeiro, em 1993. Esses projetos de lei apresentavam vinculação a projetos societários antagônicos, enquanto o primeiro representava os anseios da sociedade civil por uma educação promotora da justiça social, o segundo representava os interesses das empresas privadas, especialmente no campo da educação profissional, na qual o Sistema S e suas derivações se beneficiavam desde os anos 1940.

A lei aprovada resulta do diálogo entre esses dois projetos, com alguns avanços, mas alguns retrocessos para a educação profissional. A relação entre trabalho e educação é ampliada, a expressão mercado de trabalho presente na LDB n. 5.692/71 é substituída por mundo do trabalho: "A educação escolar deverá vincular-se ao mundo do trabalho e a prática social." (LDB 9.394/96, Artigo 1으 $\S 2$ ㅇ). Dessa maneira, ampliam-se as possibilidades formativas, tendo em vista que o mundo do trabalho abrange outros horizontes de produção da existência humana.

\subsection{ESTRUTURA e organização da educação profissional}

A Lei n. 9.394/96, em seu Art. 21 estrutura a Educação escolar da seguinte forma: 
I - Educação básica, formada pela educação infantil, ensino fundamental e ensino médio;

II - Educação superior

Ao contrário das expectativas por uma formação de Ensino Médio que integrasse os conhecimentos básicos aos gerais, a educação profissional é apresentada em um capítulo à parte, entre o da educação básica e o da educação superior. A respeito disso, nosso entendimento se coaduna com o de Moura (2007), o qual destaca que o fato da educação profissional ser posta dessa maneira na Lei relega a sua inserção na educação regular brasileira, e por não ter uma denominação que se adeque, passou a ser tratada como uma modalidade de ensino.

No Art. 39, são definidas a organização e a finalidade da educação profissional:

A educação profissional, integrada às diferentes formas de educação, ao trabalho, à ciência e à tecnologia, conduz ao permanente desenvolvimento de aptidões para a vida produtiva.

Parágrafo único. $O$ aluno matriculado ou egresso do ensino fundamental, médio e superior, bem como o trabalhador em geral, jovem ou adulto, contará com a possibilidade de acesso à educação profissional. (Lei n. 9.394, 1996, grifo nosso).

Ou seja, a educação profissional transita entre os níveis fundamental, médio e superior, entretanto como uma modalidade de ensino. Ela não está integrada a proposta de formação lato sensu em nenhum dos níveis, aparece como possibilidade, como uma formação stricto sensu ou complementar à educação geral. E isso pode ser ainda compreendido quando nos Art. 40 e 41 , essa formação profissional pode ser ofertada para além dos espaços escolares.

Art. 40. A educação profissional será desenvolvida em articulação com o ensino regular ou por diferentes estratégias de educação continuada, em instituições especializadas ou no ambiente de trabalho.

Art. 41. O conhecimento adquirido na educação profissional, inclusive no trabalho, poderá ser objeto de avaliação, reconhecimento e certificação para prosseguimento ou conclusão de estudos. (Lei n. 9.394, 1996).

A composição curricular, prevista na Lei n. 9.394/96, no que se refere ao Ensino Médio, prescreve uma formação geral e uma formação profissional no Art. 36, da seguinte forma:

§ 2ㅇ O ensino médio, atendida a formação geral do educando, poderá prepará-lo para o exercício de profissões técnicas.

$\S$ 3o Os cursos do ensino médio terão equivalência legal e habilitarão ao prosseguimento de estudos.

§ 4ำ A preparação geral para o trabalho e, facultativamente, a habilitação profissional, poderão ser desenvolvidas nos próprios estabelecimentos de ensino médio ou em cooperação com instituições especializadas em educação profissional. 
De acordo com os parágrafos acima, a educação profissional passa a ser modalidade de educação complementar à educação básica. Outro ponto de destaque do Art. 40 (que traz a articulação da educação profissional com o ensino regular e a possibilidade de formação para além dos espaços escolares) é que ele foi decisivo para que o Estado publicasse o Decreto $\mathrm{n}$. 2.208/97, cujo Art. 5 determina a separação entre a educação propedêutica e a educação profissional: "A educação Profissional de nível técnico terá organização curricular própria e independente do ensino médio, podendo ser oferecida de forma concomitante ou sequencial a este".

Esse Decreto restabelece a dualidade estrutural da educação brasileira, impondo, de maneira autoritária, ao pouco de ensino médio integrado que existia, a separação entre educação propedêutica e educação profissional (Frigotto, 2010).

Nessa mesma linha discursiva, Moura (2007) afirma que a partir daquele instrumento legal, o Ensino Médio recupera sua função meramente propedêutica, enquanto os cursos técnicos obrigatoriamente separados do Ensino Médio a partir do Decreto n. 2.208/97 passam a ser oferecidos das seguintes formas: concomitante e subsequente ao ensino médio. Na primeira, o estudante cursa ao mesmo tempo o Ensino Médio e o curso técnico, com diferentes matrículas e currículos na mesma instituição ou em instituições diferentes; a segunda forma, a subsequente, é destinada aos jovens que já concluíram o Ensino Médio.

No Capítulo destinado a educação profissional, no Art. 39, "A educação profissional, integrada às diferentes formas de educação, ao trabalho, à ciência e à tecnologia, conduz ao permanente desenvolvimento para a vida produtiva", leva a compreensão que existe uma eminente vinculação entre a educação profissional e aptidões para a vida produtiva, com currículos desenvolvidos a partir de prévia consulta às demandas de mercado, de análise de novos perfis profissionais e de novas tendências tecnológicas.

Em linhas gerais, a terceira LDB reservou um espaço módico para a educação profissional, afirmando-a como modalidade de ensino desmembrada da educação básica e, consequentemente, destinando aos decretos a estruturação e organização desse campo educacional. Fato que resultou em prejuízos para a formação integrada dos sujeitos trabalhadores.

\subsection{A concepção de formação humana proposta pela terceira LDB}

A Lei n. 9.394/96 apresenta alguns avanços no tocante à formação humana integral, embora não tenha contemplada todas as proposições do projeto original. Partimos da conceituação proposta por Ciavatta $(2005$, p.2) para analisarmos como essa formação é contemplada nessa LDB: "Como formação humana, o que se busca é garantir ao adolescente, ao jovem e ao adulto trabalhador o direito a uma formação completa para a leitura do mundo e para a atuação como cidadão pertencente a um país, integrado dignamente à sua sociedade política".

Em consonância com os preceitos apresentados acima, o Art. 35, que trata do Ensino Médio, explicita as finalidades da última etapa da educação básica, as quais compreendem: 


\begin{abstract}
I - a consolidação $E$ o aprofundamento dos conhecimentos adquiridos no ensino fundamental, possibilitando o prosseguimento de estudos;

II - a preparação básica para o trabalho e a cidadania do educando, para continuar aprendendo, de modo a ser capaz de se adaptar com flexibilidade a novas condições de ocupação ou aperfeiçoamento posteriores;

III - o aprimoramento do educando como pessoa humana, incluindo a formação ética e o desenvolvimento da autonomia intelectual e do pensamento crítico;

IV - a compreensão dos fundamentos científico-tecnológicos dos processos produtivos, relacionando a teoria com a prática, no ensino de cada disciplina. (Lei n. 9.394, 1996).
\end{abstract}

Compreendemos que o conceito de formação integrada proposto por Ciavatta (2005) está materializado nas quatro finalidades do Ensino Médio e, consequentemente, na educação profissional, uma vez que o $\S 2$ 을 do Art. 36 prevê que essa etapa, atendida a formação geral do educando, poderá prepará-lo para o exercício de profissões técnicas.

No entanto, um dispositivo dessa lei frustrou as expectativas de uma educação profissional integrada aos conhecimentos gerais, que possibilitaria a formação omnilateral da classe trabalhadora. Trata-se do Art. 40, cujo texto prescreve: "A educação profissional será desenvolvida em articulação com o ensino regular ou por diferentes estratégias de educação continuada, em instituições especializadas ou no ambiente de trabalho." (Lei n. 9394, 1996, grifo nosso).

Como já discutimos, o Decreto n. 2.208/97 foi o instrumento legal que regulamentou a organização da oferta dos cursos técnicos, determinando a oferta concomitante e subsequente, solapando o sonho da integração dos conhecimentos gerais aos profissionais. Realidade que vai de encontro às finalidades preceituadas para o Ensino Médio.

Moura (2007) chama a atenção para os sentidos que o termo articulação imprime: A impossibilidade de integração entre o Ensino Médio e a educação profissional. Em consequência disso, prevalece um currículo dual, longe do que se deseja, no sentido de uma formação humana integral.

Predominou os interesses do mercado de trabalho, cujas necessidades determinam a organização e os fins da educação profissional, em detrimento do desenvolvimento dos sujeitos, por meio da amplitude da formação, a qual tem grande potencial para oportunizar diferentes postos de trabalho. Prevaleceu assim a formação profissional com orientação stricto sensu, de acordo com as necessidades do capital.

\title{
4.3 Formação docente para a educação profissional: o silêncio da lei
}

No tocante à formação de professores para a educação profissional, a Lei n. 9.394/96 é lacônica, uma vez que não há nenhum artigo ou outro item dessa lei que aborde a especificidade 
do tema. Todavia, o Título IV, que trata dos profissionais da educação, estabelece normas sobre a formação docente de um modo geral.

Dessa forma, o Art. 61 prevê a formação de profissionais da educação, de modo a atender aos objetivos dos diferentes níveis e modalidades de ensino e as características de cada fase do desenvolvimento do educando. Essa formação se fundamenta na associação entre teorias e práticas, incluindo a capacitação em serviço e o aproveitamento da formação e experiências anteriores em instituições de ensino e outras atividades.

Ao legislar sobre a formação docente nesses termos, para todos os níveis e modalidades da educação, o legislador omite uma das grandes questões da educação profissional, considerando que esse campo de ensino apresenta especificidades que demandam uma formação condizente com as necessidades de um processo educativo que integre conhecimentos gerais e específicos de cada área, na perspectiva da formação integrada.

De forma também genérica, o Art. 62 prevê que a formação de docentes para atuar na educação básica será feita em nível superior, em curso de licenciatura plena, em universidades e institutos superiores de educação. Há também previsão de cursos de formação pedagógica para docentes no Artigo 63:

Art. 63. Os institutos superiores de educação manterão: I - cursos formadores de profissionais para a educação básica, inclusive o curso normal superior, destinado à formação de docentes para a educação infantil e para as primeiras séries do ensino fundamental; II - programas de formação pedagógica para portadores de diplomas de educação superior que queiram se dedicar à educação básica;

III - programas de educação continuada para os profissionais de educação dos diversos níveis. (Lei n. 9.394, 1996, grifo nosso).

Esses cursos são objeto da Resolução CNE/CEB n. 02/97, que dispõe sobre os programas especiais de formação pedagógica de docentes para as disciplinas do currículo do ensino fundamental, do ensino médio e da educação profissional em nível médio. Concordamos com Kuenzer (2011), quando afirma a necessidade dessa formação pedagógica para os docentes que atuam no campo da educação profissão, especialmente nas disciplinas específicas, dada a necessidade de articulação pedagógica do currículo com o mundo do trabalho.

Em detrimento da determinação do Artigo 62 da LDB 9.394/96, o Decreto n. 2.208/97 representa um retrocesso para a formação dos professores da educação profissional. Seu Artigo 9 possibilita que professores, monitores e instrutores possam ministrar disciplinas do ensino técnico, desde que comprove experiência profissional (Machado, 2013).

Portanto, no cenário da formação para a educação profissional, a Lei n. 9.394/96 não legisla de forma específica, além disso, o referido decreto precariza a formação, negligenciando a necessidade de curso em nível superior para atuar nas áreas específicas. Essa política reforça a dualidade na educação profissional, pois a formação é um dos elementos indispensáveis à qualidade do ensino, por isso, fundamental para um projeto de educação emancipatória. 


\section{CONSIDERAÇÕES FINAIS}

Em face da discussão que realizamos com base nas LDB, consideramos que a educação profissional não foi priorizada em benefício do desenvolvimento social, mas sim do capital, uma vez que os interesses das empresas privadas e do desenvolvimento econômico se sobressaíram nas políticas públicas educacionais.

A análise da estrutura e da organização desse campo educacional nas Leis n. 4.024/61, 5.692/71 e 9.394/96 evidencia que mantiveram a dualidade estrutural, a qual reproduz as condições socioeconômicas da classe trabalhadora, habilitando-os com uma formação limitada, desprovida dos princípios científicos comuns aos diversos processos produtivos. A Lei n. 5.692/71 pretendia superar essa dualidade ao universalizar a formação profissional de nível médio, no entanto essa determinação não se materializou. Por sua vez, a Lei n. 9.394 não possibilitou a assunção necessária a educação profissional, ou seja, não prescreveu a necessária integração dos conhecimentos gerais aos conhecimentos técnicos. Além disso, apartou-a da educação básica.

A formação humana integral, apesar de ser referida nas LDB, de forma mais contundente na Lei n. 9.394/96, não se materializou na prática, uma vez que se manteve sempre a dualidade, dividindo os estudantes entre o ensino propedêutico e o ensino profissionalizante. $O$ alvo das políticas públicas concretizadas na legislação educacional foi sempre preparar força de trabalho para as necessidades produtivas do capital.

No tocante à formação docente, predominou uma reticência nas LDB, com o objetivo de não comprometer o Estado com o necessário investimento financeiro que esse tema exige, dada as especificidades do campo da educação profissional. Disso decorre a polêmica sobre o entendimento dos cursos especiais previstos na primeira Lei n. 4.024/61, bem como a lacuna sobre a formação necessária para atuar nos cursos técnicos na Lei n. 5.692/71 e a situação caótica que isso gerou mediante à obrigatoriedade do $2^{\circ}$ grau profissionalizante.

Na LDB n. 9.394/96, há uma lacuna sobre a formação de professores para a educação profissional, pois essa lei prevê que a formação docente para atuar na educação básica deve ser feita em nível superior, em cursos de licenciatura plena. Não há menção para o caso específico da educação profissional. Tal omissão, a qual entendemos ter sido proposital, resultou no mandamento posto no Decreto n. 2.208/97, possibilitando que professores, monitores e instrutores pudessem ministrar disciplinas técnicas, sendo suficiente a comprovação da experiência profissional.

Em outros termos, as LDB mantiveram um modelo dual de escola, vinculada aos preceitos de uma ideologia pragmática, que tem como princípio a subordinação da educação aos interesses imediatos da realidade, entendida como mercado de trabalho. Dessa forma, a escola pública, de nível básico, gratuita, universal, laica, tecnológica e de qualidade, nunca esteve posta como uma prioridade voltada à classe trabalhadora, ao contrário, a classe dominante não tem interesse na emancipação dos sujeitos trabalhadores. Por essa razão, priva-os de uma educação 
técnico-profissional omnilateral, que englobe todos os componentes do mundo do trabalho e coloque-os em condições de disputa na sociedade capitalista.

\section{REFERÊNCIAS}

Assis, S. M. de \& Medeiros Neta, O. M. de. (jul/dez. 2015). Educação Profissional no Brasil (1960-2010): uma história entre avanços e recuos. Tópicos Educacionais, Recife, v.21, n.2. Recuperado de <https://repositorio.ufrn.br/jspui/bitstream/123456789/23171/1/Educa\%C3\%A7\%C3\%A3oPro fissionalNoBrasil_2015.pdf>.

Ciavatta, M. (2005). A formação integrada: a escola e o trabalho como lugares de memória e de identidade. Trabalho necessário. Niterói, n. 3. p. 1-20. Recuperado de http://www.uff.br/trabalhonecessario/images/TN_03/TN3_CIAVATTA.pdf

Costa, A. M. F. \& Nascimento, J. M. (2013). Reflexões sobre a formação técnica, científica e humanística no ensino de 2 o grau técnico profissionalizante a partir da Lei Decreto 5.692/71. Revista Brasileira da Educação Profissional Tecnológica. N. 6, Vol. 1, p. 40. Recuperado de file://D:/Downloads/3559-12097-1-PB\%20(2).pdf

Frigotto, G. (1993). Educação como capital humano: uma teoria mantenedora do senso comum. in G. Frigotto, A produtividade da escola improdutiva. São Paulo. Cortez. 4a. Ed. (pp. 35-68).

Frigotto, G. (2010). A relação da educação profissional e tecnológica com a universalização da educação básica. in J. Moll et. al. Educação profissional e tecnológica no Brasil Contemporâneo: desafios, tensões e possibilidades. Porto Alegre: Artmed (pp.25-41).

Gamboa, S. S. (2001). A globalização e os desafios da Educação no limiar do novo século. in J. C. LOMBARDI (Org.). Globalização, Pós-modernidade e Educação: história, filosofia e temas transversais. Campinas: Associados.

Kuenzer, A. Z. (set. 2011). A formação de professores para o Ensino Médio: velhos problemas, novos desafios. Educação \& Sociedade, Campinas, v. 32, n. 116, pp. 667-688.

Lei n. 4.024, de 20 de dezembro de 1961. Fixa as diretrizes e bases da educação nacional. Lei de Diretrizes e Bases da Educação - LDB. Brasília, DF, 1961. Recuperado de http://www2.camara.leg.br/legin/fed/lei/1960-1969/lei-4024-20-dezembro-1961-353722publicacaooriginal-1-pl.html

Lei n. 5.692, de 11 de agosto de 1971. Fixa diretrizes e bases para o ensino de 1e 20 graus, e dá outras providências. Recuperado de http://www2.camara.leg.br/legin/fed/lei/1970-1979/lei5692-11-agosto-1971-357752-publicacaooriginal-1-pl.html

Lei n. 9.394, de 20 de dezembro de 1996. Estabelece as diretrizes e bases da educação nacional. Recuperado de http://www2.camara.leg.br/legin/fed/lei/1996/lei-9394-20-dezembro-1996362578-publicacaooriginal-1-pl.html

Machado, L. R. de S. (2013). Formação de Professores para a Educação Profissional Tecnológica: perspectivas históricas e desafios contemporâneos. in D.H. Moura (Org.). Produção de conhecimento, políticas públicas e formação docente em educação profissional. Campinas, SP: Mercado das Letras, (pp.347-361). 
Manfredi, S. M. (2002). Educação profissional no Brasil. São Paulo: Cortez.

MORAES, R.; GALIAZZI, M. do C. (2016). Análise Textual Discursiva. 3. ed. Ijuí: Ed. Unijuí.

Moura, D. H. (2007). Educação básica e educação profissional e tecnológica: dualidade histórica e perspectiva de integração. Holos, Natal, v. 2, pp. 1-27. Recuperado de http://www2.ifrn.edu.br/ojs/index.php/HOLOS/article/viewFile/11/110

Rodrigues, I. da S. \& Souza, F. das C. S. (2015). Percurso histórico da formação de professores para educação profissional no Brasil (séculos XX-XXI). Anais do III Colóquio Nacional I Eixo Temático III - Formação de professores para a educação profissional. ISSN: 2358-1190. 